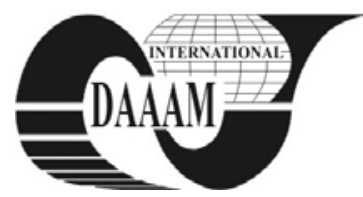

Annals of DAAAM for 2011 \& Proceedings of the 22nd International DAAAM Symposium, Volume 22, No. 1, ISSN $1726-9679$ ISBN 978-3-901509-83-4, Editor B. Katalinic, Published by DAAAM International, Vienna, Austria, EU, 2011 Make Harmony between Technology and Nature, and Your Mind will Fly Free as a Bird Annals \& Proceedings of DAAAM International 2011

\title{
SOLDERABILTY OF HIGH-PURITY ALUMINIUM WITH THE LEAD-FREE SOLDERS
}

\author{
HLAVATY, I[vo]
}

\begin{abstract}
The work deals with solderabilty of high-purity aluminium with the lead-free tin solders. Soldering was performed in the air with and without application of flux and with mechanical removal of surface oxides. Wettability measurements have shown that all lead-free solders wetted aluminium surface with wetting angle below $42^{\circ}$. The shear strength of experimental joints attained the values from 25 to $48 \mathrm{MPa}$. The study of boundary zones of fabricated joints was performed by use of EDX analysis.
\end{abstract}

Key words: solderability, aluminium, lead-free solders, cadmium-free solders

\section{INTRODUCTION}

The basis of classical solders destined for joining alumimium consists of heavy metal alloys containing Cd, Sn, $\mathrm{Pb}$, less frequently with Ag and Sb (Ruža, 1988; Koleňák 2008). For soldering aluminium, for example the solders type Sn20Cd1Ag, Sn63Pb3Zn, Zn16Cd etc, were used.

In agreement with valid legislation in EU, the solders containing lead and/or cadmium must not be used in electric equipment. Owing this reason, experiments were performed, with the aim to determine the material solderability of highpurity aluminium with use of alternative solders, which are considered for a perspective substitution of classical solders containing Pb and Cd (Chen, 1996; Liang, 2006). Only a part of experimental resuts is given in this contribution.

\section{EXPERIMENTAL}

It is supposed that a solder applicable for aluminium must contain the alloying elements which form the solid solution or intermetallic phases with aluminium, whereas their mutual solubility may be low. For example zinc creates relatively wide range of solid solution with with aluminium. Aluminium creates relatively smaller range of solid solution with $\mathrm{Ag}, \mathrm{Cu}$, $\mathrm{Mg}, \mathrm{Mn}$ and $\mathrm{Li}$. Al creates minimum zone of solid solution with tin (Ruža, 1988; Koleňák 2008; Li, 2010).

Based on the mentioned assumptions, following from the equilibrium diagrams, five alternative solders were designed with the effort to attain them as a pure metal, of eutectic and/or close-to-eutectic composition.

\subsection{Experimental material}

\begin{tabular}{|c|c|c|c|}
\hline $\begin{array}{c}\text { Solder } \\
\text { composition }\end{array}$ & $\begin{array}{c}\text { Melting point } \\
{\left[{ }^{\circ} \mathbf{C}\right]}\end{array}$ & $\begin{array}{c}\text { Thermal } \\
\text { conductivity } \\
{\left[\mathbf{W}^{-\mathbf{m}^{-1} \mathbf{K}^{-\mathbf{1}} \text { ] }}\right.}\end{array}$ & $\begin{array}{c}\text { Electric } \\
\text { conductivity } \\
\text { IACS [\%] }\end{array}$ \\
\hline \hline Sn & 232 & 63,2 & - \\
\hline Sn3.5Ag & $221 \mathrm{E}$ & 33 & 16.00 \\
\hline Sn9Zn & $199 \mathrm{E}$ & 61 & 15.00 \\
\hline Sn3.8Ag0.7Cu & $217 \mathrm{E}$ & - & 13.50 \\
\hline Sn6Ag4TiCe & $221-232$ & 48 & - \\
\hline
\end{tabular}

Tab. 1. Composition and properties of experimental solders

\begin{tabular}{|c|c|c|c|}
\hline Chemical name & Wt. \% & Symbol & Risk Phrases \\
\hline \hline Monoethanolamine & $30-60$ & Xn, C & R20/21/22-34 \\
\hline $\begin{array}{c}\text { Ammonium } \\
\text { hydrogendifluoride }\end{array}$ & $5-10$ & T, C & R25 - 34 \\
\hline Tin Chloride dihydrate & $10-15$ & None & None \\
\hline Zinc Chloride & $5-10$ & Xn, C, N & R22-34-50/53 \\
\hline
\end{tabular}

Tab. 2. Composition of experimental flux

Soldering experiments were performed with aluminium with $5 \mathrm{~N}$ (99.999\%) purity. Chemical composition of the suggested alternative solders and their properties are given in Table 1. Soldering was executed with a flux from LA-CO® \#60 company, with composition given in Table 2.

\subsection{Soldering methods and parameters}

Soldering was realised in the air, whereas two methods for removing oxides were used:

- by use of flux,

- by mechanical removing of oxides - by scraping under the layer of molten solder.

For flux-free soldering, with a mechanical removing of oxides, only the Sn6Ag4TiCe solder is destined (Koleňák, 2005; Koleňák 2011). In case of other solders, soldering was perfomed with flux application.

Heating on soldering temperature was applied by the hot plate method. Soldering temperature was selected to $20^{\circ} \mathrm{C}$ above the melting point temperature of the used solders.

\section{RESULTS}

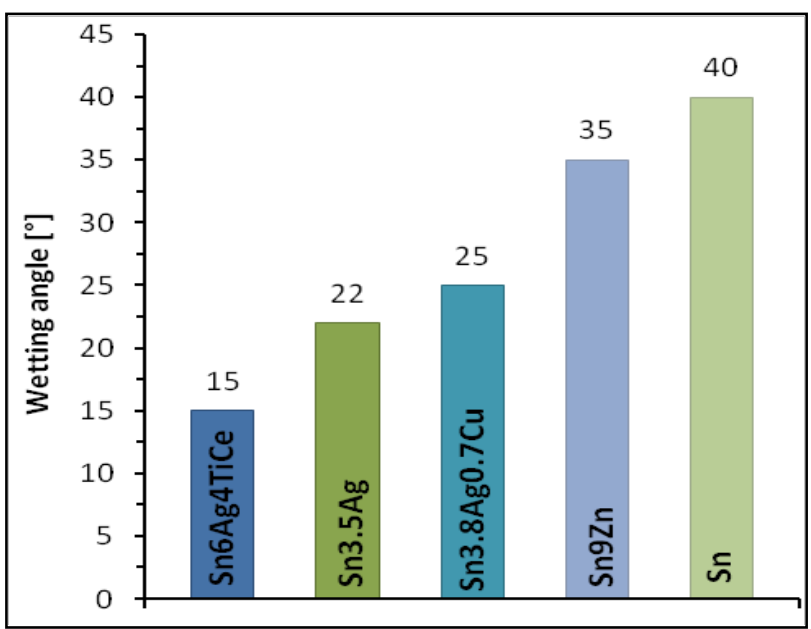

Fig. 1. Results of wetting angle measuremenst

Experiment assessment consisted of measuring the wetting angles of alternative solders on pure aluminium substrate. The metallographical cross sections from the boundary of solder aluminium were investigated. The boundary zones were assessed by use of optical microscopy, SEM and chemical 
microanalysis. The results of wetting angle measurements are given in Fig 1.

The best results of wetting were achieved in soldering with the solder type Sn6Ag4TiCe without use of flux and with mechanical removing of oxides. In case of flux application, the best results were achieved with an eutectic solder type Sn3.5Ag, containing silver, with wetting angle of $22^{\circ}$. On the contrary, the worst results were shown with the solder of pure $\mathrm{Sn}$, whereby also the theoretical assumptions were confirmed.

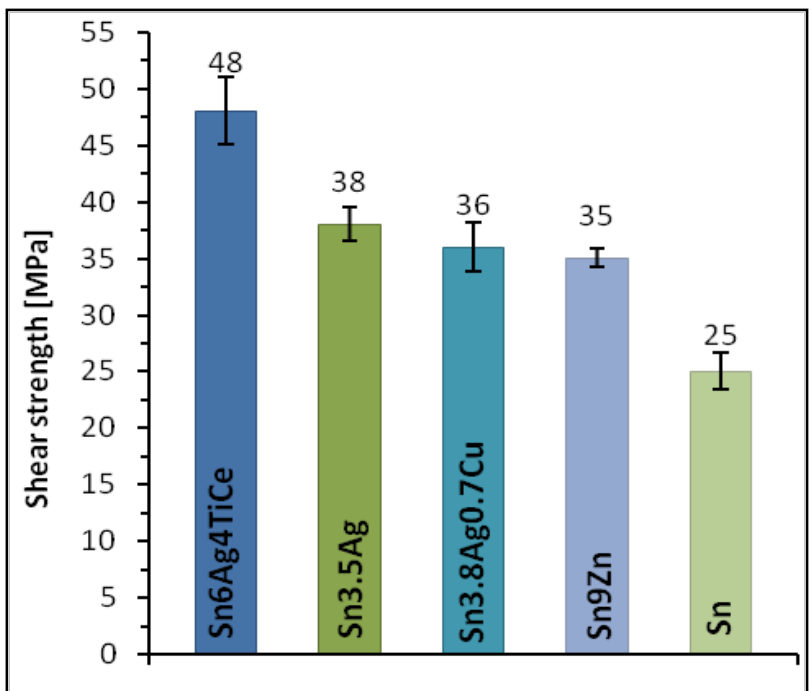

Fig. 2. Shear strength of soldered joints

Based on the results of wetting angle measurements, the test pieces for testing shear strength of soldered joints were prepared. The highest shear strength was achieved with the solder type Sn6Ag4TiCe (Martinkovič, 2010). On contrary, the lowest strength was achieved with pure tin - Fig 2 . This result is related with the value of wetting angle and interaction taking place on aluminium - solder boundary.

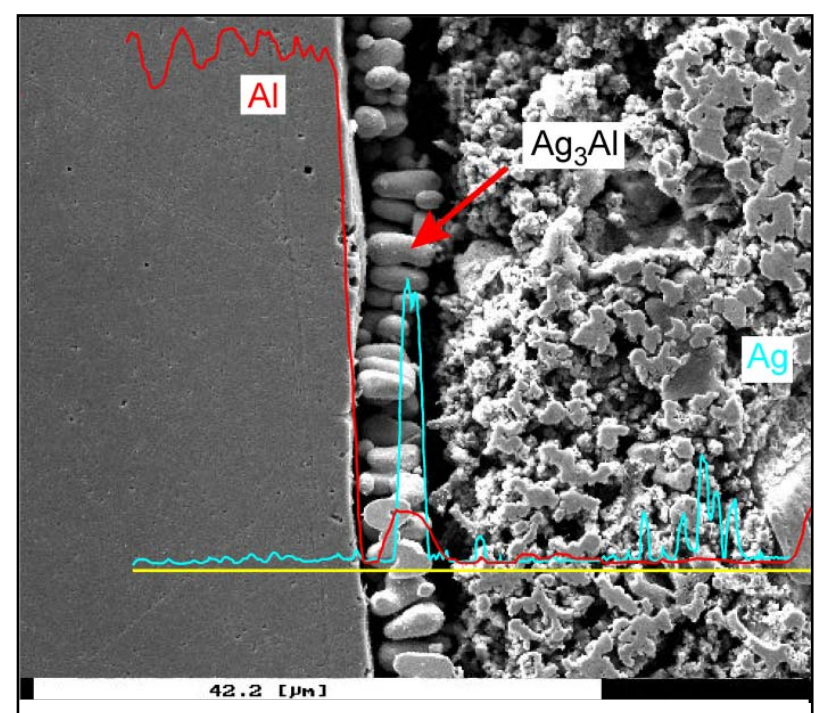

Fig. 3. Microstructure of joints Al - Sn6Ag4TiCe solder and concentration profiles of $\mathrm{Ag}, \mathrm{Al}$ elements

Transition zone was highlighted by a deep etching down of tin matrix (Fig. 3) and it is formed of a new intermetallic phase, which enhances the joint formation between the solder and $\mathrm{Al}$.

In case of Sn3.5Ag solder, soldered with the flux, a finer morphology of the new-formed phase was revealed, whereas in case of joint fabricated with Sn6Ag4TiCe solder without flux, a coarse morphology was observed, see Fig. 3.
Analysis of chemical composition has shown that the interaction of pure aluminium with the solder containing $\mathrm{Ag}$ resulted in formation of transition zone rich in $\mathrm{Ag}$ from the solder and aluminium from the soldered material.

Formation of a new $\mathrm{AgAl}$ phase, rich on $\mathrm{Al}$ is proved also by the concentration profiles of $\mathrm{Ag}$ and $\mathrm{Al}$ elements, on the boundary of parent metal of aluminium and Sn6Ag4TiCe solder - Fig. 3. (Zhong, 2002).

From the results of chemical analysis and according to the equilibrium binary diagram it may be concluded, that by aluminium - silver interaction, the $\mathrm{Ag}_{3} \mathrm{Al}$ phase is formed.

\section{CONCLUSION}

The research was aimed to study of material solderability of high-purity $\mathrm{Al}$ by use of alternative solders, free from lead and cadmium, whereas the following results were achieved:

- wetting angles on pure aluminium attained with the suggested alternative solders were determined,

- the best wetting angle $\alpha=14^{\circ}$ was achieved with the Sn6Ag4TiCe solder without use of flux,

- the best wetting angle in case of flux application $\alpha=21^{\circ}$, was achieved with the eutectic solder type Sn3.5Ag,

- the shear strength of experimental joints ranged from 25 to $48 \mathrm{MPa}$.

- it was found out that the highest effect on wettability of the studied solders was exerted by the silver content in solder,

- the metallographic analysis and X-ray microanalysis have shown that on the aluminium - solder (containing silver) boundary a new phase, rich in silver, was formed,

- the results of chemical analysis have revealed that owing to interaction of aluminium with silver, the $\mathrm{Ag}_{3} \mathrm{Al}$ phase was formed, which is responsible for wetting and formation of a diffusion bond between the pure aluminium and solder.

\section{REFERENCES}

Chen R.; Zhang Q. (1996). Mechanism of interaction between base aluminum and molten eutectic $\mathrm{Sn}-\mathrm{Zn}$ alloy. Acta Metallurgica Sinica, no. 01, ISSN: 0412-1961

Koleňák, R. (2008). Solderability of metal and ceramic materials by active solders. Forschungszentrum Dresden, ISBN 978-3-941405-03-5

Koleňák, R.; Šebo, P.; Provazník, M.; Koleňáková, M.; Ulrich, K. (2011). Shear strength and wettability of active Sn3.5Ag4Ti(Ce,Ga) solder on $\mathrm{Al}_{2} \mathrm{O}_{3}$ ceramics. Materials and Design, Vol. 32, (3997-4003), ISSN 0261-3069

Koleňák, R.; Žúbor, P. (2005). Soldering of Ceramic Materials Using Ultrasonic Energy. Welding in the World. Vol. 49, (546-553), ISSN 0043-2288

Li, J.F.; Agyakwa P.A.; Johnson C.M.; Zhang, D.; Hussain T.; McCartney D.G. (2010). Characterization and solderability of cold sprayed $\mathrm{Sn}-\mathrm{Cu}$ coatings on $\mathrm{Al}$ and $\mathrm{Cu}$ substrates, Surface \& Coatings Technology, Vol. 204, (1395-1404), ISSN 0257-8972

Liang, Y. (2006). Analysis and Countermeasure about Solderability of Aluminum Electrolytic Capacitor. Electronic Product Reliability and Environmental Testing, no. 03, ISSN: $1672-5468$

Martinkovič, M.; Drienovský, M. (2010). Comparison of mechanical properties and microstructure of lead-free solders and soldered joints. Acta Metallurgica Slovaca Conference, no. 1, (277-280), ISSN 1338-1660

Ruža, V. (1988). Pájení, 2.vydanie, (Brazing/Soldering, $2^{\text {nd }}$ ed.), SNTL/Alfa, Prague

Zhong, J.W. (2002). High Solderability Tin alloy Electroplating Technology for Aluminum and Its Alloy, Materiais Protection, no. 11, ISSN: 1001-1560 